\title{
O FORTALECIMENTO DAS OUVIDORIAS COMO INSTRUMENTO DE CONTROLE SOCIAL: ANÁLISE E IMPACTOS PARA A APLICAÇÃO DA LEI 13.460/2017
}

\author{
Camila Sanson Pereira Bastos ${ }^{1}$ \\ Carolina de Lima Cazarotto Pereira ${ }^{2}$
}

\begin{abstract}
Resumo
A gestão pública atual pressupõe atuação e foco em resultados, primando pela qualidade, transparência, lisura e adequação dos serviços públicos prestados às necessidades da sociedade. Nesse contexto torna-se relevante o papel do cidadão como principal agente de controle da qualidade desses serviços. Para isso é mister que a Administração Pública ofereça canais efetivos de atuação para o exercício do controle social. De acordo com a Controladoria-Geral da União (CGU), a Ouvidoria é considerada um relevante canal de diálogo entre o cidadão e a Administração Pública, de modo que as manifestações decorrentes do exercício da cidadania provoquem contínua melhoria dos serviços públicos prestados. Desde a criação da Ouvidoria-Geral da União (OGU) pela Lei 10.689/2004 (que alterou a denominação de Ouvidoria-Geral da República para Ouvidoria-Geral da União), a qual possui competência primária de coordenar tecnicamente as Ouvidorias do Poder Executivo Federal (conforme Decreto $n^{\circ} 4.785 / 2003$ ), uma série de normas, procedimentos e sistemas vem sendo colocada em prática no sentido de fortalecer, padronizar, orientar e expandir a atuação das Ouvidorias, não somente no Poder Executivo Federal mas também nas esferas estaduais e municipais, assim como nos demais poderes da União. O objetivo deste artigo é analisar o contexto e identificar os impactos da implementação da Lei $n^{\circ}$ 13.460/2017, um dos mais recentemente publicados instrumentos legais de participação, proteção e defesa dos direitos do usuário dos serviços públicos da Administração Pública, sob a ótica da mudança de cultura e inovação.
\end{abstract}

Palavras-Chave: Ouvidoria. Controle Social. Participação Social.

DOI:10.37814/2594-5068.2019v2.p31-39

1 Mestre em economia, regulação e concorrência dos serviços públicos pela Universidade de Barcelona. Servidora pública da Agência Nacional do Cinema - ANCINE, lotada na Ouvidoria-Geral do órgão. (camila.bastos@ancine.gov. br) (camilasanson@gmail.com)

2 Mestre em Sistemas de Gestão pela Escola de Engenharia da Universidade Federal Fluminense. Servidora pública e Ouvidora-Geral da Agência Nacional do Cinema - ANCINE. (carolina.cazarotto@ancine.gov.br) (ccazarotto@ yahoo.com.br) 


\begin{abstract}
Public administration currently presupposes performance and focus on results, offering quality, transparency, smoothness and adequacy of public services provided to the needs of society. In this context the role of the citizen as main agent of quality control of these services becomes relevant. For this it is necessary that the Public Administration offers effective channels of action for the exercise of social control. According to the Office of the General Comptroller of the Federal Government (CGU), the Ombudsman's Office is considered a relevant channel for dialogue between citizens and public administration, so that manifestations arising from the exercise of citizenship lead to continuous improvement of public services rendered. Since the creation of the General Ombudsman's Office by Law 10.689 / 2004 (which changed the name of Ouvidoria-Geral da República to Ouvidoria-Geral da União), which has primary responsibility for technically coordinating the Ombudsman Offices of the Federal Executive Branch (according to Decree No. 4,785 / 2003), a series of norms, procedures and systems have been put into practice in order to strengthen, standardize, guide and expand the performance of Ombudsman Offices, not only in the Federal Executive Branch but also in the state and municipal spheres, as well as in the other powers of the Union. The purpose of this article is to analyze the context and identify the impacts of the implementation of Law 13,460 / 2017, one of the most recently published legal instruments for participation, protection and defense of user rights of public services of the Public Administration, from the point of view of the change of culture and innovation.
\end{abstract}

Keywords: Ombudsman. Social Control. Social Participation. 


\section{INTRODUÇÃO}

A democracia tem como princípio fundamental o poder que emana do povo e que é exercido em seu nome. No Brasil, como Estado Democrático de Direito, são conferidas atribuições para fiscalização e controle dos governantes em todas as instâncias. Atualmente, após a falta de participação do cidadão nessas funções de controle, estamos num momento de resgate de cidadania.

Assim, depois do fim da ditadura militar, a partir da década de 1980, há uma crescente criação de organizações sociais para proteção da cidadania. Elas surgiram primeiramente nas empresas privadas, depois nas prefeituras e, gradualmente, na esfera federal. Com a Emenda Constitucional 45/2004, as Ouvidorias de justiça passaram a ter caráter constitucional (CALLEGARI e DE MELLO, 2016).

A Ouvidoria é um instrumento de controle social na medida em que objetiva satisfazer o interesse público dando oportunidade para o cidadão se manifestar acerca da atuação de órgãos públicos. Sendo assim, exercendo ou não o controle da instituição através da Ouvidoria, é caracterizado o interesse público, dando abertura ao cidadão para se manifestar sobre a atuação das entidades públicas. Desse modo, independentemente de se estar exercendo ou não o controle institucional por meio da Ouvidoria, o cidadão exerce o controle social porque a atividade precípua da entidade é o interesse social (SOUSA, 2016).

De acordo com OLIVEIRA (2005), a Ouvidoria reforçou uma aspiração social que veio juntamente com a nova postura cidadã, que demandava uma gestão eficaz , transparente e honesta do bem público. Também foi exigida uma postura da administração a serviço do cidadão por meio da criação de canais de comunicação que permitissem a participação popular.

Uma maior transparência é conseguida através da participação social direta realizada por meio da Ouvidoria. A população, com essa forma de participação, pode interagir com a administração para formular políticas públicas, diminuir erros, melhorando assim o serviço e efetivamente sendo ativa na execução da gestão pública (ANTUNES, FREITAS e RIBEIRO FILHO, 2016). Esse papel vem sendo reconhecido pela população conforme pesquisa recente que aponta que $73 \%$ dos cidadãos que interagiram com as Ouvidorias tiveram solução dos temas reclamados (ASSOCIAÇÃO BRASILEIRA DE OUVIDORES, 2018).

A perspectiva da qualidade foi introduzida quase simultaneamente ao momento em que a Administração Pública voltava suas atenções aos usuários. Essa foi uma das principais conquistas trazidas pelo modelo gerencial (ABRUCIO,1997).

Segundo Schikmann (2010), o novo contexto da gestão pública parte de uma sociedade que exige foco de atuação em resultados, onde a qualidade e a adequação dos serviços às necessidades dos usuários são consideradas aspectos relevantes para o desempenho da administração. A aplicação desse conceito, na prática, exige aumento da flexibilidade, da prontidão e da capacidade de adaptação dessas organizações, implicando o uso de novas tecnologias, com a modernização da estrutura normativa, organizacional e de pessoal.

Imbuída desses princípios, em 1995 foi criada a Ouvidoria-Geral da República, como parte da estrutura do Ministério da Justiça. O estado de São Paulo, em 1999, promulgou a Lei de proteção ao usuário do serviço público, determinando a criação de Ouvidorias em todos os órgãos públicos 
estaduais. Em 2003, a Ouvidoria-Geral da República foi transferida para a estrutura da Controladoria-Geral da União (CGU), e posteriormente teve seu nome alterado para Ouvidoria-Geral da União (OGU), tendo competência para exercer a coordenação técnica das Ouvidorias do Poder Executivo federal. Como já citado, em 2004, foi criada a Emenda Constitucional $n^{\circ} 45$, que determinava a criação de Ouvidorias no Poder Judiciário e no Ministério Público, no âmbito da União, Estados, Distrito Federal e Territórios (OUVIDORIA-GERAL DA UNIÃO, 2016).

Com a criação da OGU, foram publicadas normas que visavam o fortalecimento e a regulamentação das atividades da instituição. O Decreto 5.683, de 24 de janeiro de 2006, conferiu à Ouvidoria-Geral da União competência para orientar as Ouvidorias de órgãos integrantes do Poder Executivo Federal e para fomentar a excelência de atendimento dessas Ouvidorias.

Também com esse objetivo, em 2009, foi publicado o Decreto 6.932/2009 (BRASIL, 2009), posteriormente revogado pelo Decreto 9.064/2017 (BRASIL, 2017), que instituiu a carta de serviços ao cidadão, estabelecendo assim o dever dos órgãos e entidades do Poder Executivo federal de elaborar e divulgar uma carta com os serviços ao usuário para informar o cidadão sobre os serviços prestados pelo órgão.

Esse é um instrumento de transparência das atividades prestadas por órgãos públicos e de orientação aos cidadãos para verificarem se os serviços são adequados às expectativas da população, que pode, dessa forma, ser informada sobre quais são os serviços disponíveis, tendo assim maior possibilidade de conhecer seus deveres e exigir seus direitos. Também é uma ferramenta importante para a Administração Pública porque favorece a gestão por resultados, quando se busca uma melhora constante dos serviços públicos. Para o servidor público, a carta também é relevante porque torna mais visível o seu trabalho e cria procedimentos para a sua rotina (LESSA, 2009).

Outro marco normativo no campo de atuação das Ouvidorias foi a Lei de Acesso à Informação (LAI), Lei 12.527/2011 (BRASIL, 2011), que criou o serviço de informação ao cidadão, possibilitando assim maior transparência nas atividades do governo federal. Esse elemento fundamental para exercer a democracia - o controle dos atos de governo, a fiscalização do poder - é mais uma ferramenta que tem o cidadão para o controle e a participação social.

Essa Lei está em consonância com paradigmas da Constituição Federal, como a democracia e a cidadania, quando estabelece que é regra o acesso aos atos dos administradores, sendo o sigilo, a exceção. Também há o alinhamento quanto à proteção dos direitos fundamentais dos cidadãos, o que gera uma Administração Pública cada vez mais efetiva e transparente, o que reforça os ideais de uma Ouvidoria Pública. A LAl aprimora e consolida a consciência de participação coletiva (NASCIMENTO e PARCA, 2016).

Em 2014, visando integrar e sistematizar as Ouvidorias do Poder Executivo, traçando deveres, princípios e espécies de manifestações, inclusive estabelecendo prazos para resposta, a Ouvidoria-Geral da União publicou a Instrução Normativa 01/2014 (OUVIDORIA-GERAL DA UNIÃO, 2014). Dois anos depois, em 2016, foi publicada a portaria interministerial 426 (BRASIL, 2016), que tornou obrigatória a criação de canais de recebimento de manifestações de Ouvidoria para órgãos e entidades que recebam recursos federais por meio de transferências voluntárias.

Também visando a qualidade e o controle social, em junho de 2018, entrou em vigor a Lei 13.460/2017 (BRASIL, 2017), que dispõe sobre a participação, proteção e defesa dos direitos do 
usuário dos serviços públicos da Administração Pública e é objeto deste artigo por ser relevante para as Ouvidorias Públicas.

\section{ANÁLISE E IMPACTOS DA LEI 13.460/2017}

O código de defesa do usuário dos serviços públicos, Lei 13.460/2017 (BRASIL, 2017), tem seu fundamento no art. $37, \S 3^{\circ}$, inciso I da Constituição Federal, que prevê que os usuários dos serviços públicos devem ter meios de "participar" da Administração Pública. Um desses meios é a possibilidade de reclamar sobre a qualidade dos serviços públicos. O diploma legal é aplicado à Administração Pública direta e indireta da União, dos Estados, do Distrito Federal e dos Municípios e, subsidiariamente, aos serviços públicos prestados por particular.

A nova lei, no seu art. $2^{\circ}$, traz um significado mais amplo para Serviço Público. A definição abrange a prestação direta de bens e serviços por órgãos e entidades públicas, atividades realizadas por particulares e até atividades administrativas, também conhecidas como "atividades meio", onde o usuário do serviço prestado é a própria Administração Pública.

A aplicação da lei considera usuário qualquer pessoa física ou jurídica que se beneficie ou utilize, seja de forma efetiva e direta ou mesmo de forma potencial, um serviço público. Isso significa que em situações em que o cidadão possui um serviço disponível, como por exemplo o Sistema Único de Saúde, mesmo que não o utilize, ele é considerado um usuário daquele serviço.

Como a lei visa ampliar os direitos e a proteção aos usuários dos serviços públicos, ela não se sobrepõe a outros instrumentos normativos tais como o Código de Defesa do Consumidor (Lei 8.078/1990), Lei de Acesso à Informação (Lei 12.527/2011) e Lei de Procedimento Administrativo (Lei 9.784/1999), que devem ser utilizados de forma complementar ou subsidiária.

A Ouvidoria é um dos canais mais importantes para o exercício da participação e controle social, logo possui papel fundamental na aplicação dessa lei. O instrumento normativo apresenta inovações significativas que fortalecem o controle social e a democracia, no entanto, alguns pontos merecem atenção e são objetos de ponderações.

Quanto aos princípios para prestação de serviço e atendimento ao usuário, é correto afirmar que a lei trouxe os parâmetros de presteza, acessibilidade, racionalidade, proporcionalidade, qualidade, segurança, cortesia e eficiência para a prestação dos serviços públicos, assim como o cumprimento desses princípios pelo próprio destinatário (através do controle social), pelos meios e canais de acesso previstos no diploma legal ou por órgãos fiscalizadores (controles interno e externo).

No campo de atuação das Ouvidorias, uma inovação que merece destaque foi a criação dos Conselhos dos Usuários. O Conselho poderá ser consultado quanto à indicação do Ouvidor, o que legitima a representatividade e minimiza o risco de captura política. Essa, segundo a lei, representa a forma de participação dos usuários no acompanhamento da prestação e na avaliação dos serviços públicos. Tais conselhos serão compostos de maneira a observar os critérios de representatividade e pluralidade das partes interessadas, para que a representação seja equilibrada. A escolha dos representantes será feita em processo aberto ao público e diferenciado por tipo de usuário a ser representado. 
O art. 10 da Lei acrescentou um ponto positivo para a consolidação das Ouvidorias. Foi estatuído que as Ouvidorias são o canal de entrada das manifestações. Além disso, foi determinado que cada Poder e esfera de governo deve dispor de atos normativos específicos acerca da organização e funcionamento desses setores. Isso significa que, além da aplicação da lei através da Instrução Normativa 05/2018 OGU, que regulamenta pontos importantes, cada órgão poderá criar seus instrumentos específicos para legitimar a ação e o trabalho da Ouvidoria.

Outro ponto que fortalece as Ouvidorias está no art. 11 do referido diploma legal, que traz a garantia de que, em nenhuma hipótese, se recusará o recebimento de manifestações formuladas nos termos da Lei 13.406/2017, sob pena de responsabilidade do servidor público. Com isso, o usuário tem a garantia de que sua manifestação será aceita e seus direitos serão respeitados.

Outra inovação que favorece o controle social está no art. 12 da lei. Há uma uniformização dos procedimentos administrativos relativos à análise e ao tratamento das manifestações. Estabelece-se que serão observados princípios de eficiência e de celeridade, visando sua efetiva resolução.

O prazo de atendimento às manifestações é um ponto de atenção, já que houve um aumento no tempo de resposta ao usuário. $\mathrm{O}$ art. 16 diz que o prazo para resposta conclusiva passa a ser de trinta dias, prorrogáveis por mais trinta, mediante justificativa. Ou seja, dez dias a mais se comparado ao que havia sido determinado na IN 01/2014 da OGU, que estabelecia um prazo de vinte dias, prorrogáveis por mais dez quando justificado. No entanto, um ponto positivo é que a lei também estabelece prazos para que as áreas ou órgãos provocados pela Ouvidoria se manifestem em até vinte dias (prorrogáveis por mais vinte). Essa era uma dificuldade operacional em termos de fluxo de trabalho, portanto a lei, a partir dessa obrigatoriedade de prazos e ao uniformizar procedimentos, facilita muito o trabalho de acompanhamento e até mesmo de cobrança das Ouvidorias em relação às demais áreas e agentes públicos vinculados.

Dentre as atribuições precípuas estabelecidas na lei para as Ouvidorias, destaca-se a promoção da participação do usuário na Administração Pública, em cooperação com outras entidades de defesa do usuário. Isso cria a obrigação das Ouvidorias cooperarem entre si e com as entidades de defesa do usuário, reforçando seu papel de protagonista na proteção desses direitos.

Um ponto igualmente relevante implica a participação ativa da Ouvidoria no controle de qualidade e avaliação do serviço prestado ao usuário. Isso deverá ser feito através do acompanhamento da prestação dos serviços, visando a garantir sua efetividade; da proposição de aperfeiçoamentos na prestação dos serviços; do auxílio na prevenção e correção dos atos e procedimentos incompatíveis com os princípios estabelecidos nessa lei; da proposição de adoção de medidas para a defesa dos direitos do usuário, em observância às determinações dessa lei; do recebimento, análise e encaminhamento às autoridades competentes das manifestações, acompanhando o tratamento e a efetiva conclusão das manifestações de usuário perante órgão ou entidade a que se vincula; e da promoção da mediação e conciliação entre o usuário e o órgão ou a entidade pública, sem prejuízo de outros órgãos competentes.

Um possível retrocesso e um contraponto diante da IN Conjunta $n^{\circ} 01 \mathrm{CRG} / \mathrm{OGU}$ é que a lei passa a criar a obrigação de que a manifestação do usuário para a defesa de seus direitos seja identificada. Apesar de o parágrafo primeiro do dispositivo prever que a identificação do requerente não conterá exigências que inviabilizem sua manifestação nem exigirá a motivação, a identificação 
obrigatória para o manifestante é algo que pode inibir a manifestação do usuário, principalmente quando se trata de denúncia, o que não contribui com a efetiva participação e controle social. Observa-se ainda que essa impossibilidade de manifestação anônima ainda vai contra o que entende o Supremo Tribunal Federal (BRASIL, SUPREMO TRIBUNAL FEDERAL, 2017).

Felizmente, para reduzir esses impactos negativos, foi acrescentado ao art. 10 da lei, o parágrafo $1^{\circ}$, que permite atender a casos em que a identificação é precária, sem estabelecer exigências maiores para continuidade e tratamento da manifestação.

Para realizar os objetivos das Ouvidorias, principalmente o controle social, no art. 14 é informado que as Ouvidorias deverão receber, analisar e responder, por meio de mecanismos proativos e reativos, as manifestações encaminhadas por usuários de serviços públicos. Também como forma de avaliar o serviço prestado fica estabelecido que serão elaborados, anualmente, relatórios de gestão, que consolidarão as informações das manifestações, e, com base nelas, serão apontadas falhas e sugeridas melhorias na prestação de serviços públicos. São itens obrigatórios do relatório: o número de manifestações recebidas no ano anterior; os motivos das manifestações; a análise dos pontos recorrentes; e as providências adotadas pela Administração Pública nas soluções apresentadas. Tal documento será encaminhado à autoridade máxima do órgão a que pertence a unidade de Ouvidoria. Como forma de transparência, tal relatório será disponibilizado integralmente na internet.

Cabe destacar que a IN 01/2014 da OGU previa que as Ouvidorias Públicas deveriam enviar à OGU, no mínimo semestralmente, relatórios com os dados das manifestações. Quando a lei prevê um relatório anual, diminui a periodicidade e consequentemente o controle, o que poderia ser considerado um retrocesso. Entretanto, o fato de o prazo estar presente em uma lei (em comparação a uma instrução normativa) cria uma certeza sobre a imposição dessa obrigação, além de gerar responsabilidade para os envolvidos caso não se cumpra o dever.

Alguns pontos relevantes identificados pela Associação Brasileira de Ouvidores/Ombudsman $(A B O)$ no anteprojeto de Lei Orgânica das Ouvidorias, e que deveriam ter constado da Lei 13460/2017, merecem destaque, tais como a obrigação de mandato para exercer o cargo de Ouvidor, de dedicação exclusiva destinada à gestão da Ouvidoria e de designação por ato do dirigente máximo dos órgãos ou entidades. Com isso, ter-se-ia maior independência e autonomia de atuação do Ouvidor, tão necessária ao exercício de sua função.

Por fim, a ABO acrescenta que, sem prejuízo das atribuições estabelecidas em outros regulamentos, a Ouvidoria como área organizacional deve atuar com independência de manifestação, autonomia de avaliação das demandas que receber, devendo os dirigentes máximos da entidade preservar e garantir essas prerrogativas. Sendo essa ausência de afirmação um dos pontos de maior conflito interno para a realização do trabalho e das atividades das Ouvidorias.

\section{CONCLUSÕES}

Da análise dos pontos da norma, observa-se que as inovações trazidas pelo código dos usuários do serviço público têm um viés preponderantemente positivo, mas com aspectos que poderiam ser objeto de ponderação. 
Essas inovações não somente fortalecem e empoderam as Ouvidorias como também trazem um nível maior de exigência, prontidão, responsabilização e capacidade de trabalho aos envolvidos.

Para que sejam efetivamente implementadas as mudanças sugeridas pela norma, é necessário que sejam estabelecidos novos processos, adaptação da estrutura organizacional, aquisição de recursos (pessoal, físico e tecnológico) e alteração ou criação das normas de regimento interno e de padrões de trabalho da Ouvidoria.

A capacitação dos servidores da equipe da Ouvidoria também é aspecto relevante no sentido de reforçar a conscientização interna de que a Ouvidoria assume, a partir deste diploma legal, um papel proativo e de protagonismo. Esse mesmo entendimento deve ser expandido num segundo momento a toda organização, uma vez que a finalidade da legislação é proporcionar uma mudança de cultura, não somente na Ouvidoria, mas em todo o órgão.

Para consolidar a mudança, é necessário um plano de comunicação robusto interna e externamente, que transmita aos servidores seus deveres como prestadores do serviço e aos usuários o papel de beneficiários dessa lei.

\section{REFERÊNCIAS}

ABRUCIO, F. L. O impacto do modelo gerencial na Administração Pública: um breve estudo sobre a experiência internacional recente. Cadernos ENAP, Brasília, n. 10, p. 1-52, 1997.

ANTUNES, C. K. S.; FREITAS, N. R. D. B.; RIBEIRO FILHO, J. F. Ouvidoria: inter-relação entre o controle social e controle interno, 2016. Disponível em: <http://www.ipea.gov.br/Ouvidoria/images/stories/doc/OUVIDORI_inter_relacao.pdf>.

ASSOCIAÇÃO BRASILEIRA DE OUVIDORES. Ouvidorias têm cumprido seu papel, 2018. Disponível em: <http:// www.abonacional.org.br/artigo/116>.

BRASIL. Decreto 6.932, 2009. Disponível em: <http://www.planalto.gov.br/ccivil_03/_ato2007-2010/2009/decreto/ d6932.htm>

. Lei 12.527. [S.I.]: [s.n.], 2011. Disponível em: <http://www.Ouvidorias.gov.br/Ouvidorias/legislacao/leis/lei-de-acesso-a-informacao>.

. Portaria Interministerial 424, 2016. Disponível em: <http://www.Ouvidorias.gov.br/Ouvidorias/legislacao/portarias/portaria_interministerial_no_424_de_30_de_dezembro_de_2016_revisada.pdf $>$. D9094.htm>.

Decreto 9094, 2017. Disponível em: <http://www.planalto.gov.br/ccivil_03/_Ato2015-2018/2017/Decreto/

htm>.

. Lei 13.460, 2017. Disponível em: <http://www.planalto.gov.br/ccivil_03/_ato2015-2018/2017/lei/L13460.

SUPREMO TRIBUNAL FEDERAL. HC 133148. [S.I.]. 2017.

CALLEGARI, J. A.; DE MELLO, M. P. Ouvidorias: controle social das instituições como direito fundamental, 2016. Disponível em: <http://www.publicadireito.com.br/artigos/?cod=ebd774c929a7f6c7>. Acesso em: 29 maio 2018.

CONTROLADORIA-GERAL DA UNIÃO; OUVIDORIA-GERAL DA UNIÃO. Instrução Normativa conjunta 01/2014, 2014. Disponível em: <https://www.cgu.gov.br/sobre/legislacao/arquivos/instrucoes-normativas/in-crg-ogu-01-2014. pdf>

FLYNN, N. Public sector management. Nova York/Londres: Harvester Wheatsheaf, 1990. p. 113.

GIANCOLI, B. P.; PIRES, A. C. M. A Condição Jurídica do Consumidor Usuário de Serviços Públicos: Análise Sistêmica do Código de Defesa do Consumidor Frente a Edição da Lei 13.460/2017. XXVI CONGRESSO NACIONAL DO CONPEDI. São Luís do Maranhão: CONPEDI. 2017. p. 121-137. 
LESSA, R. O. Carta de serviços ao cidadão: ferramenta de transparência no setor público, 2009. Disponível em: <http://www.e-gestaopublica.com.br/carta-de-servicos-ao-cidadao-ferramenta-de-transparencia-no-setor-publico/>.

OLIVEIRA, João Elias de. Ouvidoria Pública brasileira: a evolução de um modelo único. In: VISMONA, Edson Luiz (Org.). A Ouvidoria brasileira: dez anos da Associação Brasileira de Ouvidores-Ombudsman. São Paulo: Imprensa Oficial do Estado de São Paulo, 2005. p. 45-54.

NASCIMENTO, D. T. R.; PARCA, T. D. L. L. A importância da Lei de Acesso à Informação no desenvolvimento da cidadania participativa e no controle da res publica, 2016. Disponível em: <https://www.portaldeperiodicos.idp.edu.br/ cadernovirtual/article/view/1200/720>

OUVIDORIA-GERAL DA UNIÃO. Instrução Normativa 01, 2014. Disponível em: <http://www.Ouvidorias.gov.br/Ouvidorias/legislacao/in/in-cgu-04.pdf>.

OUVIDORIA-GERAL DA UNIÃO, 02 jun. 2016. Disponível em: <http://www.Ouvidorias.gov.br/cidadao/conheca-a-Ouvidoria/historia-das-Ouvidorias>. Acesso em: 29 maio 2018.

SCHIKMANN, R. Gestão Estratégica de Pessoas: bases para a concepção do curso de Especialização em Gestão de Pessoas no Serviço Público. Gestão de pessoas: bases teóricas e experiências no setor público. Organizado por Marizaura Reis de Souza Camões, Maria Júlia Pantoja e Sandro Trescastro Bergue. Capítulo 1. Brasília: ENAP, 2010.

SOUSA, A. M. L. Controle social na Administração Pública: eficácia da Ouvidoria no Tribunal de Contas do Estado do Tocantins, 2016. Disponível em: <http://www.conteudojuridico.com.br/artigo,controle-social-na-administracao-publica-eficacia-da-Ouvidoria-no-tribunal-de-contas-do-estado-do-tocantins, $57116 . \mathrm{html}>$ 